\title{
Market Strategies for the Commercial Exploitation of Shape Memory Alloys
}

\author{
N.B. Morgan and C.M. Friend
}

SRC1, SEAS, Cranfield University, Shrivenham, Swindon, Wilts SN6 8LA, U.K.

\begin{abstract}
Recent research and development in the area of shape memory alloys (SMA) continues to yield novel and unique results. The strategic and market issues addressed in this paper seek to recognise the potential of shape memory alloy actuators and their future role in product design. The paper considers current market conditions through life cycle analysis and recognises that the diffusion of shape memory alloys into mainstream design usage will only come about through the successful targeting of innovative customers. For this to occur, the differentiating material function of shape memory must be promoted and perceived as adding value to the product function. Consideration is given to the commercialisation of SMA actuators and the role of an R\&D/Market interface. The paper states that for SMA actuators to become commercially viable the physical and mechanical properties of commercially available shape memory alloys must be consolidated and future R\&D focused on design properties relevant to applications.
\end{abstract}

\section{INTRODUCTION}

Shape Memory Alloys are a generic class of alloys that display a mechanical and thermal memory effect. The unique phenomena associated with the memory function occur due to a solid state phase change known as the thermoelastic martensitic transformation. The diffusionless nature of this type of transformation means that they are fully reversible and involve no change in atomic distribution or chemical composition.

The shape change effects that may be employed using these alloys consist of [1] :-

- One-Way Memory : Where an apparently plastically deformed material will return to its original shape when heated.

- Two-Way Memory : Where an alloy may be thermally cycled between two memorised shapes.

- Superelasticity : Where very large but spontaneously recoverable strains may be achieved.

Further reading on thermoelastic transformations and shape memory alloys may be obtained from the extensive literature $[2,3,4$,$] .$

Of the different alloys that display the shape memory effect only NiTi and $\mathrm{Cu}$ based alloys have proven commercially viable with useful engineering properties.

The following paper considers the differentiating benefits of using shape memory alloys as a source of product innovation and differentiation. Strategies are considered for future market environments and applications. 


\subsection{Shape Memory Alloys as Actuators}

Actuation is the controlled production of work output or energy release. It is likely that the main use of shape memory alloys in the future will be as actuators operating through the conversion of thermal energy into kinetic energy and work output.

The use of these alloys as solid state actuators offers many benefits [5] :-

- High recovery forces

- Large recoverable output strains

- Different actuation modes (linear, bending, torsion)

- High work output per unit volume or mass

It is perhaps the large strains and high work output that offer most opportunities for innovative design with SMA's. Graphically we can consider how the material function of the shape memory effect differentiates them from other actuating materials such as piezoelectrics and magnetostrictives, Figure 1a.

When considering the differentiating benefits of SMA actuators some disadvantages should also be considered. Figure 1b shows how compared to other possible actuators SMAs suffer from low efficiency (i.e. high loss actuation) and very poor response times or actuation frequencies. Successful applications will build on SMA strengths whilst taking into account its weaknesses.

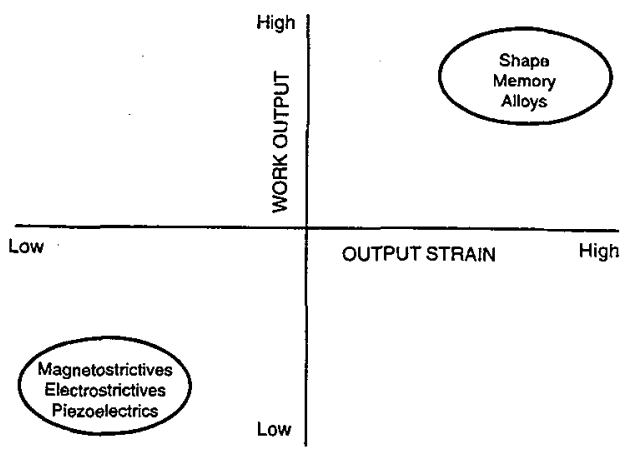

a) Advantages

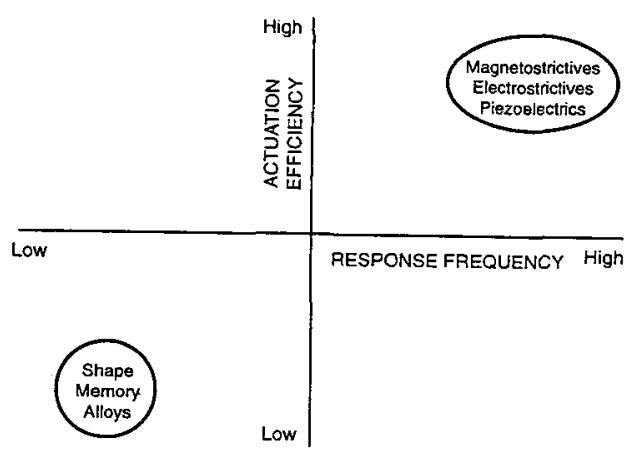

b) Disadvantages

Figure 1. The differentiating material function of shape memory alloy actuators

Shape memory alloys offer great opportunities for innovation when used within structures or as stand alone components. To successfully promote and encourage the commercial acceptance of SMA's, market strategies must be considered.

\section{THE SHAPE MEMORY ALLOY AWARENESS AND ASSIMILATION STRATEGY}

The role that new products play in gaining and maintaining competitive advantage within high technology industries is widely recognised and understood [6]. However, the high costs involved in producing new shape memory alloy products and the many application barriers that also exist, often prevent SMA applications coming to fruition.

Figure 2 shows that the primary barrier to SMA applications is that of awareness. Few engineers and designers are aware of SMA's and their potential as an engineering material. In order to increase this 
awareness, shape memory alloys and the unique advantages that may be gained through their use should be promoted to those engineers and designers seen as innovators in their particular industries.

However for these engineers and designers to then assimilate the idea of shape memory properties with real applications a number of secondary barriers must also be overcome. These include the need for accurate property characterisation and design codes, the comparatively high cost and poor workability of some alloys and the need for thermomechanical fatigue data.

Strategies focused on achieving certain market objectives through appropriate R\&D and promotion could increase the market opportunities for shape memory alloys whilst making the whole product development process much more efficient. By following an awareness and assimilation strategy that concentrates on application barriers, a simultaneous increase in SMA applications may occur leading to shape memory alloy market growth.

\section{Barriers to Market Application}

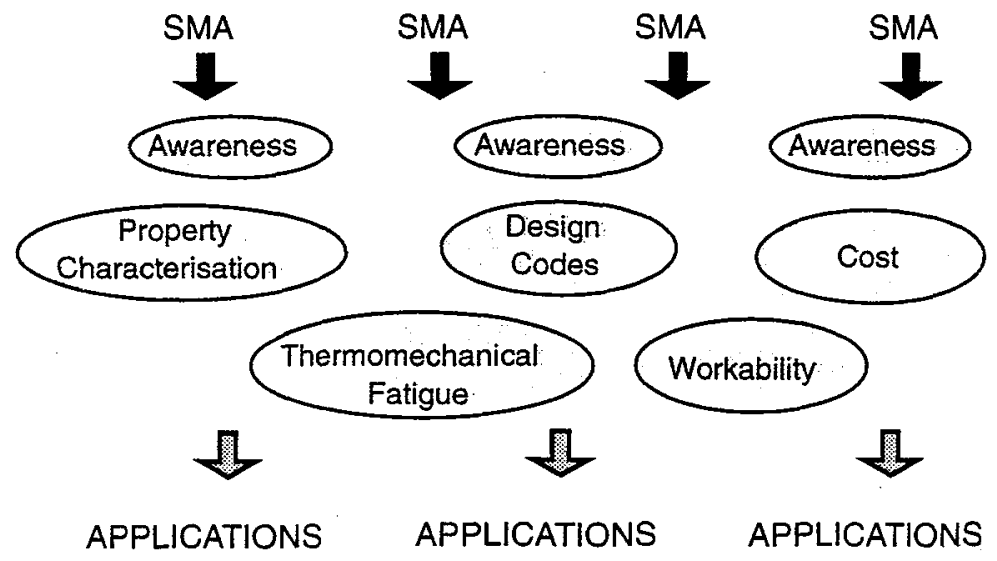

Figure 2. The Awareness and Assimilation Barriers to Shape Memory Alloy Applications

\subsection{Application Diffusion}

The concept of the 'product life cycle' or PLC (Figure 3) allows us to consider strategies for SMA's commercial future [7].

The stage of development within an industry is an important consideration within any business strategy [8]. The PLC is a useful tool when considering technological and market strategies for shape memory alloys, it suggests that different SMA application strategies may be required at different times and that future research and development can be planned around the historic and present sales trend.

Although shape memory alloys have been in existence for some years, in many potentially lucrative markets they are still in the introduction phase. It is these markets where manufacturers and small to medium business units should focus their strategic efforts.

Figure 3 describes how the diffusion of shape memory alloys through innovators and early adopters within identified market segments may correspond to shape memory alloy sales growth.. 


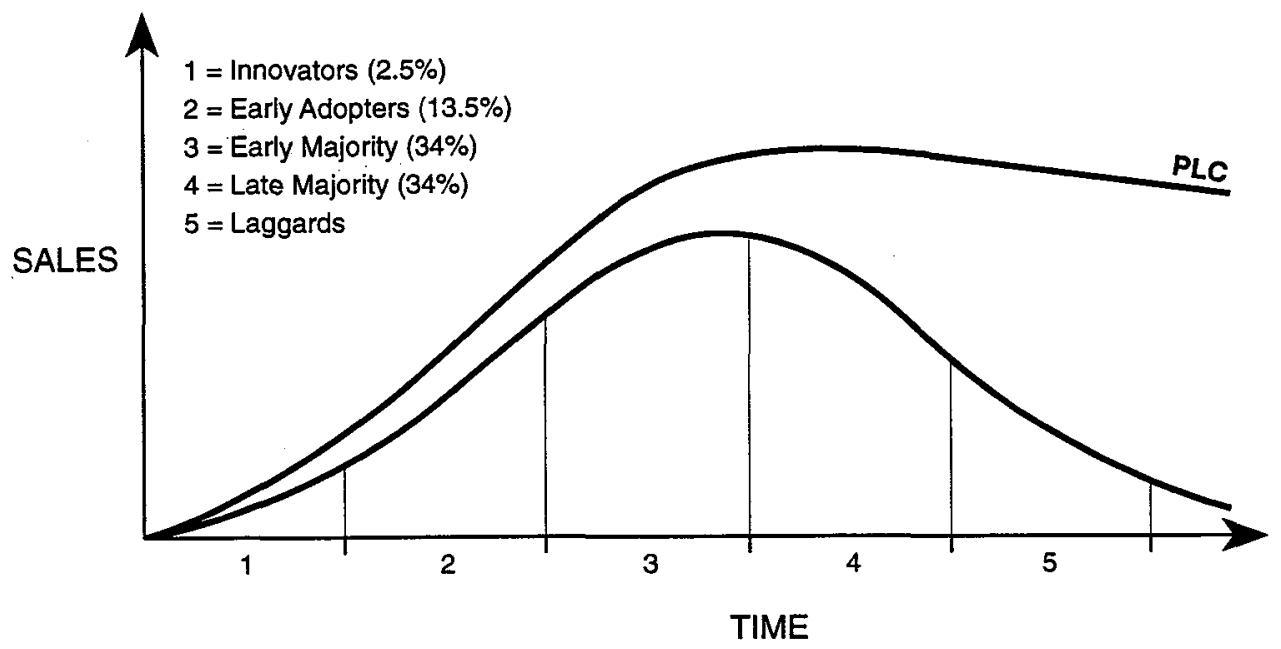

Percentages represent non cumulative $\%$ of potential adopters over time

Figure 3. The Diffusion Of Innovation Within The Product Life Cycle

During the introduction phase, profits are likely to be low or even negative and product strategies should aim to diffuse shape memory alloys into the target market through those customers or manufacturers considered to be innovative. Careful thought and investigation will identify who the market innovators and early adopters are likely to be and promotion and advertising should aim to build awareness and encourage trial amongst them. The user and commercial value that may be added to their products through the use of shape memory alloys should thus become apparent.

It must also be stressed to designers that although the use of shape memory alloys may increase the unit cost of the product, cost reduction is not always of overriding importance in gaining competitive advantage. High value added products arising from the use of shape memory alloys may command high profit margins within a particular market segment as long as the product differentiation is of genuine value to the user/customer. If this strategy is to be employed successfully then it is likely that the product is aimed at a particular niche in a market segment and will thus require a very focused approach when considering potential markets. Equally it may be that a reduction in manufacturing costs through innovative design and the use of shape memory alloy actuators will actually result in no change of price or even a reduction in price. Again for this strategy to work the customer must be identified and the product given the appropriate added value.

\subsection{Research and Development for Assimilation and Application Diffusion}

For shape memory alloys to diffuse into real actuator applications and markets, systematic R\&D on all design and product relevant properties must be carried out. Failure to do this will prevent the full potential of shape memory alloys from being realised. Shape memory alloys still face barriers to the type of diffusion process described because of the lack of knowledge on relevant properties (e.g. cyclic stability under load) and the many technical difficulties and processing constraints. Properties and phenomena that are inherent to the SMA such as transformation temperature, hysteresis profiles, cyclic stability etc. need to be properly and reliably evaluated so as to provide the type of data essential for the design of high technology SMA products and subsequent commercial acceptance.

To achieve cost effective and accurate property evaluation, backward and forward integration from the designer and manufacturer may be necessary. Increasing alliances between universities and SMA manufacturers could reduce the cost of research while increasing its commercial value and concentrating on the secondary barriers to application [9]. In addition, many products will require collaboration with the 
end user or those who have particular expert knowledge within the market segment. This type of collaboration would help create an $\mathbf{R} \& \mathbf{D}$ /Market interface focusing the research onto the market diffusion of commercially available shape memory alloys. SMA manufacturers should not be afraid of losing profits or academic property through backward or forward integration but rather regard it as an opportunity for growth and as an investment for future commercial success.

Allied to this commercial interface and inter-disciplinary information flow is the increasing need for expert networks. A solid international network in the area of shape memory alloys would not only facilitate the exchange of information but may also attract investment from industrial innovators keen to exploit the product potential of the shape memory effect.

It can be seen that the selection of appropriate customers and markets is the key to the long term development and diffusion of shape memory applications. Market segmentation should therefore proceed any new product development and information about both macro and micro-segment environments must be an essential input of market strategies.

\section{INTERACTIVE STRATEGIES AND MARKET SEGMENTS}

To date, shape memory alloy based products have tended to result from SMA product strategies driven by the inherent shape memory effects. In this way, new applications for shape memory alloys have resulted from the proactive strategy of 'technology push'.

'Demand pull' on the other hand, emphasises the fact that a potential market must be matched with the resources of the shape memory business. Conventional materials have tended to have their properties dictated by the product design and in this respect the design may be thought of as the property driver. This is a more reactive strategy that concentrates on market needs and highlights the need for application relevant research.

Both reactive market opportunities and proactive technological opportunities need to be present for successful innovation through shape memory alloys. By careful market analysis and segmentation it may be possible to combine both a reactive strategy responding to market requests for innovation and proactive market segmentation resulting from technological initiative. However for this type of interactive strategy to work the SMA manufacturer and supplier must be responsive to the product design criteria and equally the design engineer must be aware of the shape memory alloy as an engineering material and be able to have confidence in its reliability.

The medical industry in particular is requiring higher performance, more functional materials and devices. The relevant developments in these areas are already exerting a pull on shape memory alloy development and this is likely to intensify as we enter the next century.

\subsection{The Medical Environment}

As demonstrated by the high number of biomedical applications presented at the Shape Memory and Superelastic Technologies Conference 1997 there is already a proactive focus from SMA manufacturers and researchers onto the medical market. In recent years surgical techniques and biomedical materials have shown significant growth and medical engineering is now a highly opportunist market segment where NiTi (Nitinol), shown to have a biocompatibility equal to 316 stainless steel [10] may make a real contribution to improving medical treatments.

Political, economic, social and technological forces will lead to a number of key factors which will influence the medical market and ultimately dictate whether SMAs prove to be successful in creating innovation and competitive advantage within the industry :

\section{Political}

- Increased private health care

- Industrial and economic growth leading to improved health care for the countries involved

- Less defence spending 


\section{Economic}

- More private sector money for medical Research and Development

- Medical device manufacturers will invest in R\&D and look for alliances to create competitive advantage

\section{Social}

- Higher life expectancy

- Increase in remedial surgery

\section{Technological}

- Growth of associated technologies (i.e. optical engineering, medical physics etc)

- Increase in non-invasive surgery

\section{CONCLUSIONS}

This paper has sought to examine some of the issues associated with the application of shape memory alloys within commercial markets. The differentiating benefits of certain shape memory properties offer real opportunities for product innovation. If this potential is ever going to be fully realised however, consideration should be given to how these market opportunities can be best exploited. Both reactive, market opportunities and proactive, technological opportunities need to be present for successful innovation through SMAs.

Customers or manufacturers known to be innovative within the chosen market segments should be targeted to diffuse the alloy into mainstream use. It should be pointed out that the cost of the alloy may not prevent competitive advantage being achieved if its use results in high added value.

The paper also concludes that for shape memory alloys and SMA products to diffuse into markets successfully, R\&D must be carried out on relevant properties for product application. Increasing alliances between universities and SMA manufacturers may facilitate this type of research.

\section{References}

[1] Friend C.M., "The mechanisms of shape memory", European Symposium on Martensitic Transformation and Shape-Memory Properties, Aussois, France, 1991

[2] Perkins J., J. of Mat. Sci. and Eng. 51 (1974)

[3] Duerig T.W., Melton K.N., Stockel D., Wayman C.M., Engineering aspects of shape memory alloys (Butterworth-Heinmann Ltd, London, 1990) pp. 3-21

[4] Jackson C.M., Wagner C.M., Wasilewski R.J., Nitinol-The alloy with a memory (NASA, Washington D.C., 1972)

[5] Stoeckel D., Advanced Materials and Processes. (Oct 1990) 33-38

[6] Porter $\mathrm{m}$., Competitive advantage: creating and sustaining superior performance (Free Press, New York, 1985)

[7] Christopher M., McDonald M., Marketing: an introductory text (Macmillan Press Ltd, London, 1995)

[8] Loveridge R., Pitt M., The strategic management of technological innovation (John Wiley and Sons, Chichester, 1990) pp. 39-61

[9] Kaounides L., Advanced materials, corporate strategies for competitive advantage (FT management reports, Pearson Professional Ltd, London, 1995)

[10] Dutta R.S., Madangopal K., Gadiyar H.S., Banerjee S., Brit. Corr. J. 28 (1993) pp. 217-221 